Catchline (head of first page only) International Journal of Injury Control and Safety Promotion, Vol. X, No. X, Month 2005, xxx$x x x$

Running heads (verso) J.D. Blitvich and G. K. McElroy.

(recto) Waterslide injury prevention

Article Type: Short Report

\title{
Waterslide exit velocities, user behaviours and injury prevention
}

\author{
J. D. BLITVICH *, and G. K. MCELROY
}

School of Human Movement and Sport Science, University of Ballarat, Vic, Australia

Correspondence $\quad *$ Corresponding author. School of Human Movement and Sport Sciences; University of Ballarat, PO Box 663, Ballarat, Vic, Australia, 3350. Email: j.blitvich@ballarat.edu.au

This study describes exit velocities, body positions and spacing of waterslide users to provide evidence for appropriate supervision strategies for waterslide use. 267 waterslide descents were analysed. Common body positions included sitting, lying head-first or feet-first, and kneeling. Exit velocities, influenced by body position and movement on the slide, ranged from $1.69 \mathrm{~m} / \mathrm{s}$ to $5.64 \mathrm{~m} / \mathrm{s}$. Velocities were sufficient to crush cervical vertebrae (Stone 1981) in every trial, indicating the risk inherent in the activity. Velocity was highest for users in a standing position. Standing descent decreased the base of support and elevated centre of gravity, contributing to an increased possibility of over-balancing, potentially resulting in injury. The forward facing seated position allows control of descent velocity and rapid dissipation of velocity on entry. To enhance a low risk environment, supervisory practices should ensure users are adequately separated; seated and facing forwards; and clear the 'landing area' quickly.

Keywords: Waterslides; injury prevention; risk management; exit velocity, supervisory practice

AMS Subject Classification: WA: 250-292

\section{Introduction}

Pool patrons enjoy waterslides and centre managers attest to their role in increasing pool attendances. One centre reported a 50\% attendance increase in the month following installation of a new slide (Barbieri 2000). However, the inclusion of waterslides increases injury risk, and steps are required to minimise this risk. Whilst most waterslide injuries are minor, such as cuts, abrasions and dental injuries (Stokes 1985), some are serious, including paralysis from spinal injury (Baggoley, et al. 1983). Collisions with other users is a common cause of injury (Gordon \& Stevens, 1988). 


\section{Methods and materials}

A waterslide complex at a large regional aquatics centre was monitored on a hot summer day. Two slides, one open and one enclosed, terminated in a common stand alone splash-pool (Figure 1). Two hundred and sixtyseven descents from the open slide were observed, including a 30-minute non-fee session. Exit velocity was measured by radar (Stalker Pro Digital Sports Radar). Side and front view video-recordings were made of descents for later assessment of body position. Time codes were added to video-tapes, for measurement of time between consecutive descents.

Insert $\quad$ Figure 1 here

\section{Results and discussion}

\subsection{Velocity and body position}

Exit velocity ranged from $1.69 \mathrm{~m} / \mathrm{s}(6.1 \mathrm{kph})$ to $5.63 \mathrm{~m} / \mathrm{s}(20.3 \mathrm{kph})$, exceeding those considered sufficient to crush $(1.22 \mathrm{~m} / \mathrm{s}$ ) cervical vertebrae (Stone, 1981). Hence, there is potential for catastrophic injury should the head impact a solid object. Velocities varied with body position, and with what could be described as level of confidence. Timid or cautious users reduced their velocity by increasing friction, for example by pressing against the sides of the slide. Despite signage instructing users to be seated and facing forward, various behaviours were observed. Waterslide users were in the recommended position in $57 \%$ of descents. Table 1 provides body position and velocity data.

Insert Table 1 here

Whilst the single highest exit velocity was a sitting descent $(5.64 \mathrm{~m} / \mathrm{s})$, the next two highest velocities were both standing descents $(5.55 \mathrm{~m} / \mathrm{s}$ and $5.53 \mathrm{~m} / \mathrm{s})$. For one of these, the slide user dived into the splash pool. The combination of a high velocity descent and the change in body position from standing to the diving action resulted in an unsteady dive. As the splash-pool was relatively small, and waist deep for the typical participant, it is possible that impact could occur with the bottom or opposite side wall of the pool. Diving should be forbidden.

The highest average velocity occurred during standing descents, where only the feet contacted the slide. Five standing descents were observed, all during the 'free session' when slide usage was greatest. Standing descents result in decreased base of support and elevated centre of gravity, both contributing to an increased possibility of over-balancing, and consequent elevated injury risk.

A quarter of descents were head first, $19.5 \%$ on the stomach; and $6 \%$ on the back. Head first descents provided minimal protection of the head and cervical spine, and reached velocities sufficient to crush cervical vertebrae should impact occur. Head first entries should be permitted only in specifically designed slides and 
splash-pools. Appropriate design features include adequate depth and a relatively large proportion of the slide’s final section gradually sloping underwater, to progressively reduce exit velocity (Turner 1988).

In some descents, slide users rocked from one side of the slide to the other, during the ride. In the extreme, this action could result in injury if the user unintentionally comes over the side of the open tube.

More than $50 \%$ of descents were in a seated position which provides good vision, sizeable contact with the slide, and an ability to slow descent. Upon water entry, velocity is quickly decreased because the body position provides considerable frontal resistance. This body position should be encouraged.

\subsection{Spacing}

Adequate spacing between users minimises the potential for contact injuries. For the observed waterslide, a lifeguard at the top of the slide, in visual contact with the guard observing the splash-pool, verbally advised riders to commence. Time between users varied, with gaps greater than one minute, through to 12 occasions where sliders formed a chain, entering the water within one second of each other. When forming a chain, the front user slowed descent until the person following made contact.

To encourage adequate spacing between riders, Baggoley and Radford (1983) recommended payment per descent, rather than per unit time. Rushing and carelessness is more likely if users are hurrying to have another ride. In this study, commencement of the 'free session' resulted in greatly increased usage. In the 90 minutes before the 'free session', 84 descents occurred, while in the 34-minute free session, 204 descents took place including 83 descents with gaps of 5 seconds or less between splash-pool entries. The close proximity of descents provides little time for a lifeguard to assist a user in difficulty, nor does it provide much opportunity for the next user to react if the person ahead experiences trouble.

Lifeguards actively supervised users and maintained orderly control of the waterslide, but did not intervene regarding body position in descent. During this study, one collision occurred in the splash-pool when a waterslide user travelling head first on his stomach descended at a greater speed than the person ahead, who was seated facing forwards. The collision did not result in injury.

\section{Conclusion}

Waterslides can provide great enjoyment for aquatic centre patrons, resulting in increased attendances and contributing to the viability of a centre. However, exit velocities indicate the potential for severe injury and it is vital that appropriate steps are taken to prevent injury. The study findings reinforce that best practices in supervision must be applied, specifically through:

- $\quad$ appropriate body position during descent (sitting, facing forward is recommended)

- adequate time gaps between users

- effective application of waterslide rules through conscientious lifeguard supervision, with supportive centre management.

With suitable injury prevention and risk management strategies, complexes with waterslides can enjoy the increased patronage that accompanies them and waterslide users can safely participate in this recreation activity. 


\section{References}

BAgGOLEY, C. and RADFORD, A. 1983 Waterslides - The new recreation. A study to determine prospects for injury prevention. Australian Council for Health, Physical Education and Recreation, $100,15-18$.

BARBIERI, K. 2000 New ride at Camelbeach increases attendance by $50 \%$ on first month. Amusement Business, 112, 24-25.

GoRdon, C.J. and StEVENS, K.L.H. 1988 Waterslides - are safety standards sliding? Archives of Emergency Medicine, 5, 216-222.

StOKES, A.N. 1985 Waterslide accidents. New Zealand Dental Journal, 81, 114-116.

STONE, R.S. 1981 A rationale for rating pools with diving boards (Arthur D. Little Study No 4). Arthur D. Little Inc (Cambridge, Ma: Publisher).

TURNER, A. 1988 Waterslides - The North American experience. Leisure Management, 8, 30-32.

See over for Table 1 and Figure 1 
Table 1. Velocity and Body Position

\begin{tabular}{lcccc}
\hline Body Position & $\begin{array}{c}\text { Average } \\
\text { Velocity } \\
(\mathbf{m} / \mathbf{s})\end{array}$ & $\begin{array}{c}\text { Maximum } \\
\text { Velocity } \\
\mathbf{( m / s )}\end{array}$ & $\begin{array}{c}\text { Minimum } \\
\text { Velocity } \\
\mathbf{( m / s )}\end{array}$ & $\begin{array}{c}\text { Number of } \\
\text { Descents }\end{array}$ \\
\hline Standing & 4.22 & 5.55 & 2.64 & 5 \\
Feet first on stomach & 4.04 & 4.78 & 3.28 & 3 \\
Feet first on back & 4.00 & 5.33 & 2.17 & 24 \\
Head first on stomach & 3.93 & 5.22 & 2.44 & 52 \\
Kneeling & 3.68 & 4.53 & 2.47 & 7 \\
Head first, lying on back & 3.67 & 4.44 & 2.66 & 16 \\
Side on & 3.58 & 4.28 & 2.94 & 7 \\
Sitting & 3.28 & 5.64 & 1.72 & 152 \\
Sitting backwards & 1.69 & 1.69 & 1.69 & 1 \\
\hline Total & & & & 267 \\
& & & & \\
\hline
\end{tabular}




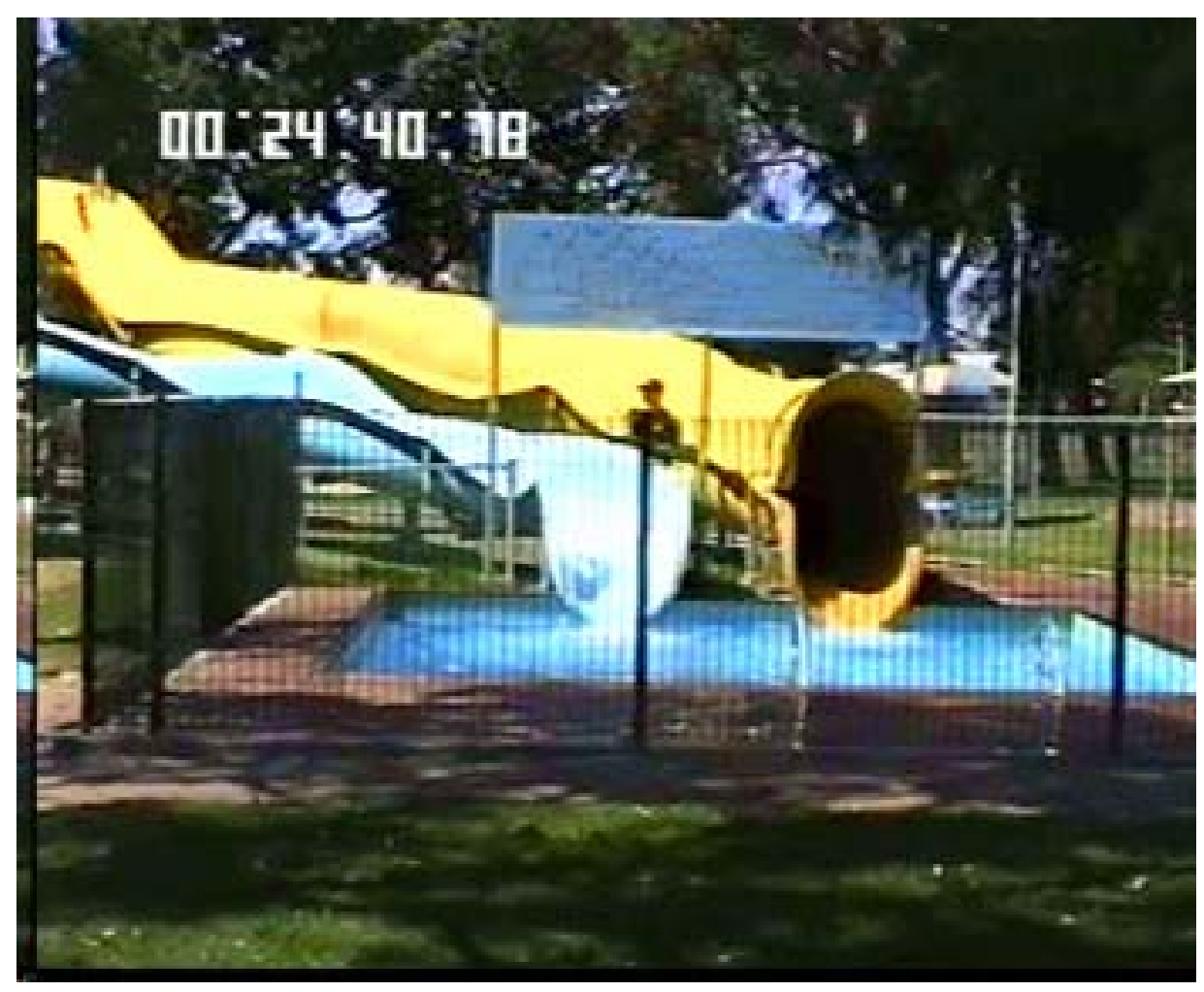

Figure 1: Waterslides 